\title{
RETROSPECTIVE ANALYSIS OF COMMON CAUSES FOR ADMISSIONS OF DIABETIC PATIENTS TO INTERNAL MEDICINE DEPARTMENT
}

OF ALEXANDRIA MAIN UNIVERSITY HOSPITAL

Mohamed Ahmed Badr, Fathy Zakarya Elsewy, Mai Hesham Mohammed Badra, Mahmoud Abdulaziz Mahmoud Salim

Department of Internal Medicine, Faculty of Medicine, University of Alexandria

\begin{tabular}{|c|}
\hline INTRODUCTION \\
\hline $\begin{array}{l}\text { DM and its complications are the most common conditions to require hospitalization than any } \\
\text { other medical condition globally and require a longer period of hospital stay. Type 2DM } \\
\text { patients have a higher frequency of admissions than type 1DM. Globally, the most common } \\
\text { cause of admissions and mortality in DM patients, especially in type } 2 \text { DM was } \\
\text { cardiovascular complications. } \\
\text { Diabetic patients are predisposed to acute and chronic complications which are the main } \\
\text { drivers of hospital admission than diabetes itself. Acute complications include; DKA, HHS, } \\
\text { infections, and normo-osmolar nonketotic hyperglycemic state. Chronic complications are } \\
\text { further classified into microvascular and macrovascular complications. Macrovascular } \\
\text { complications are divided into: coronary artery disease, cerebrovascular disease, and } \\
\text { peripheral artery disease. Microvascular complications include: diabetic nephropathy, } \\
\text { retinopathy, and neuropathy. } \\
\text { Knowing the common causes for hospital admissions in diabetic patients will enable us to } \\
\text { plan resources effectively and address the important risk factors that contribute to the increase } \\
\text { in hospitalization among diabetic patients. Reduction of hospitalization among diabetic } \\
\text { patients will tremendously reduce the high admission costs incurred and reduce the } \\
\text { overstretch of health facilities. }\end{array}$ \\
\hline
\end{tabular}

\section{AIM OF THE WORK}

This study aimed to find out the common causes for admissions of diabetic patients to the Medical Unit of Alexandria Main University Hospital from $1^{\text {st }}$ January 2019 to $1^{\text {st }}$ January 2021, their risk factors, and mortality rates.

\section{PATIENTS AND METHODS}

This was a retrospective case series study design where the medical records of diabetic patients admitted to the Medical Unit of the Main Alexandria University Hospital, from $1^{\text {st }}$ January 2019 to $1^{\text {st }}$ January 2021 were reviewed.1004 files of diabetic patients were reviewed. The following data was recorded from patients records; bio-demographic data, past medical history of hypertension, dyslipidemia, smoking, common causes for admissions, BP on admission $\mathrm{mm} \mathrm{Hg}$, Hbalc\%, RBS $\mathrm{mg} / \mathrm{dl}$, TG $\mathrm{mg} / \mathrm{dl}$, total cholesterol $\mathrm{mg} / \mathrm{dl}$, type of diabetes, period of diabetes, treatment given, duration of hospital stay and admission outcomes (died, or discharged with improvement, or discharged with sequelae of the cause).

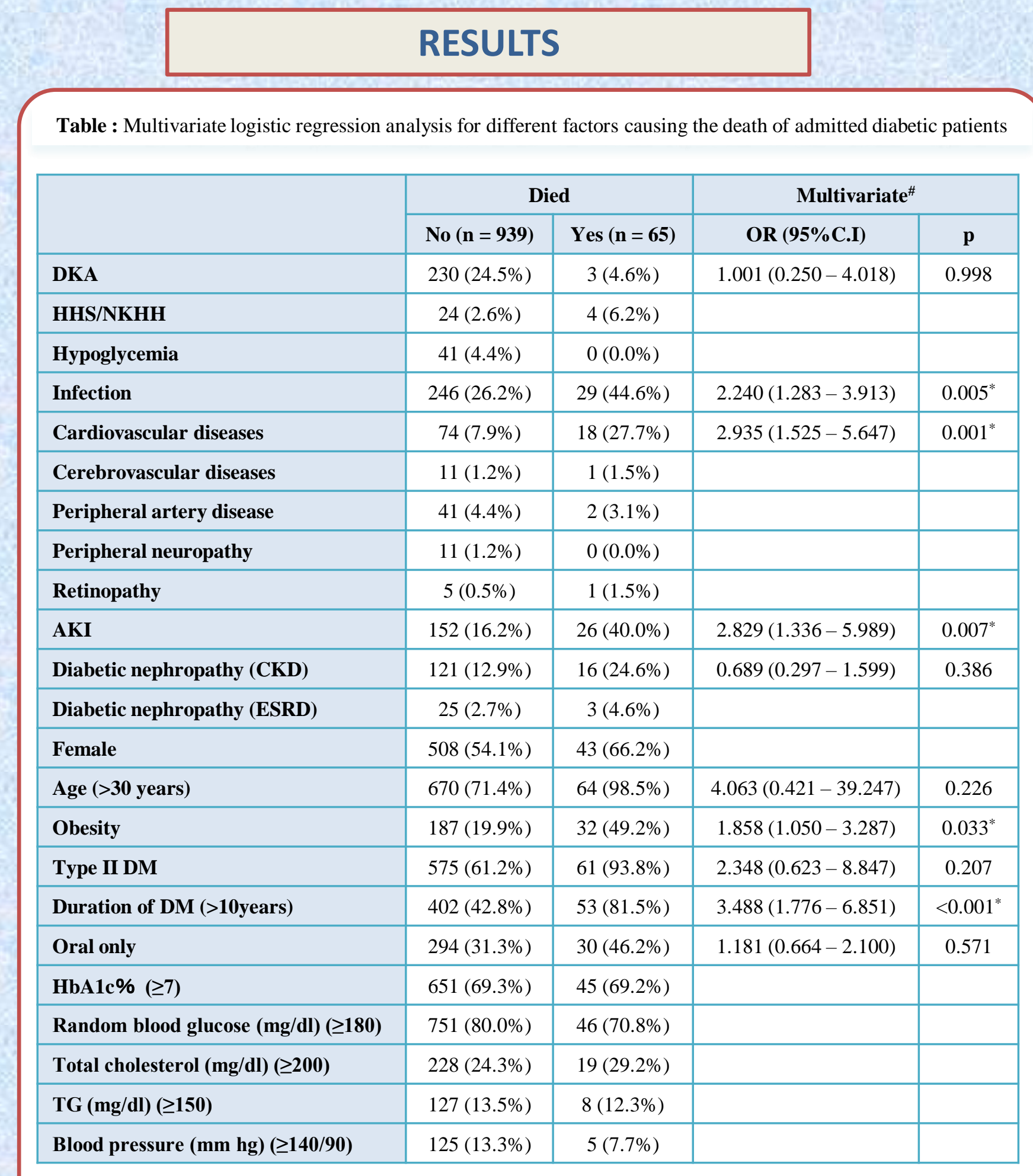

Qualitative data were expressed using Number (\%)
OR. Odd's ratio CI. Considence

OR: Odd's ratio C.I: Confidence interval $\quad$ LL: Lower limit UL: Upper Limit p: p-value for Odd's ratio $\begin{array}{ll}\text { OR: Odd } s \text { ratio C.I: Confidence interval } & \text { LL: Lower limit UL: Upper Limit } p \text {; } p \text {-value for Odd } \$ \text { ratio } \\ \text { for comparing between DKA and non-DKA } & \text { \#: All variables with p }<0.05 \text { was included in the multivariate } \\ * \text { *: Statistically significant at } \mathrm{p} \leq 0.05 & \text { AKI: Acute kidney injury }\end{array}$

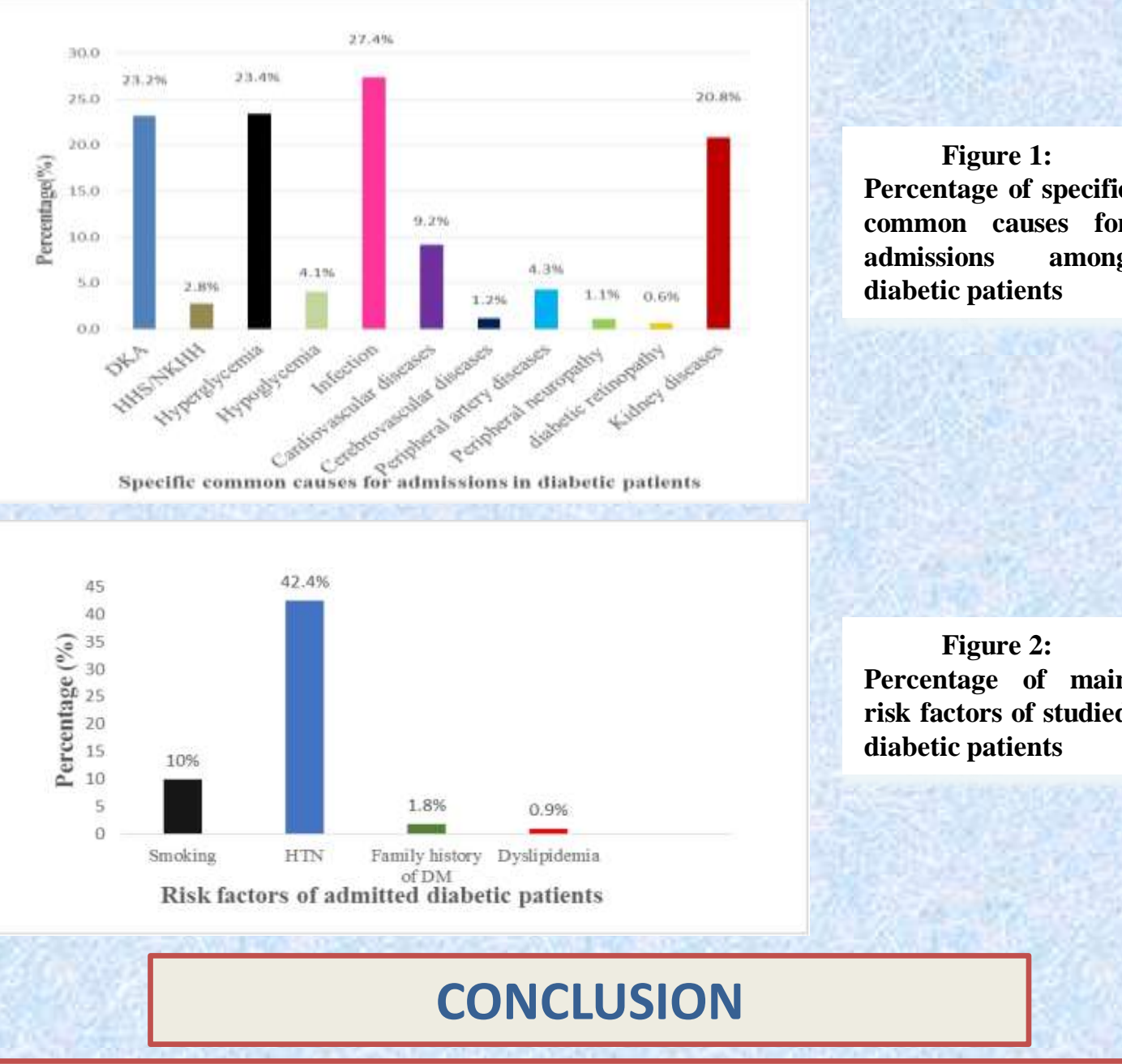

1- The most common primary reasons for a diabetes-related admission are associated with infections, DKA, diabetic kidney diseases, cardiovascular diseases, and peripheral arterial disease.

- This study investigated risk factors for inpatient admissions amongs patients with DM, adding important knowledge of risk factors associated with these events in the community. The most common reported risk factors were hypertension and smoking.

- Infection, cardiovascular diseases, acute kidney injury (AKI), Obesity, and duration of DM more than 10 years are significantly independent risk factors that causing death of admitted diabetic patients.

20210Alexandria Faculty of Medicine
CC-BY-NC

